\title{
Biuret Toxicity Symptoms in Citrus Leaves Mimics Cell Senescence Rather Than Nutritional Deficiency Chlorosis
}

\author{
D.S. Achor ${ }^{1}$ and L.G. Albrigo ${ }^{2}$ \\ Horticultural Sciences, University of Florida, IFAS, Citrus Research and Education Center, 700 \\ Experiment Station Road, Lake Alfred, FL 33850
}

\begin{abstract}
AdDitional INDEX wORDs. chloroplasts, mineral deficiency, ultrastructure, urea
Aвstract. Permanent chlorosis of leaves on plants fertilized with urea containing high levels of the contaminant biuret has been observed in several crops including citrus. Little has been reported as to the cellular changes that result from such chlorosis. Branches from 'Ruby Red' grapefruit (Citrus paradisi Macfadyn) and 'Hamlin' orange [C. sinensis (L.) Osbeck] were sprayed with urea solutions containing $1.05 \%$ biuret. As visible symptoms developed, leaf tissue samples were prepared for transmission electron microscopy. For comparison purposes, leaves from similar trees showing chlorosis from age-related senescence and $\mathrm{Zn}$ deficiency were also sampled. The progressive development of chlorosis in biuret-affected leaves was characterized by: the loss of starch, thylakoidal and granal membranes in chloroplasts along with the enlargement and increase in number of plastoglobuli or lipid bodies. The lipid bodies were liberated alone or in association with membrane vesicles to the cytoplasm and vacuoles. The number and volume of the individual chloroplasts became smaller. Concurrent loss of cytoplasmic content and the enlargement of the vacuolar space were also observed in the biuret affected leaf tissue. Similar findings were observed in the cells of senescent leaves. In cells of leaves showing nutritional deficiency, losses in cytoplasmic content and vacuolar enlargement were observed but there was neither complete loss of thylakoidal or granal membranes nor the release of lipids from the plastids. It was concluded that 1) the cytological characteristics of the biuret-affected samples were more similar to age-related senescent samples than to chlorosis from $\mathrm{Zn}$ deficiency and 2) that complete loss of the lipid bodies from the chromoplasts to the cytoplasm and vacuole in the biuret-affected samples and in age-related senescence in citrus leaves was responsible for the permanent nature of the chlorosis.
\end{abstract}

Sprays containing foliar urea as a nutritional supplement have become common in the Florida citrus industry (Albrigo, 1999, 2002). More than 50,000 ha have been sprayed in some years. Biuret is a natural by-product contaminant in the production of urea and occurs at higher concentrations as the process is carried out under elevated temperatures to increase the production rate of urea. Chlorosis (yellowing) of leaves treated with urea containing high levels of the contaminant biuret has been observed in several crops including citrus (Albrigo, 2002; Albrigo and Grosser, 1996; Gooding and Davies, 1992; Iyengar et al., 1976; Jones, 1954; Oberbacher, 1954; Sanford et al., 1954).

In apple (Malus $\times$ domestica Borkh.) leaves, urea itself contributes to leaf damage but urea toxicity is usually expressed as a burn rather than chlorosis (Khemira et al., 2000). Coffee (Coffea arabica L.) can apparently withstand levels of biuret as high as $2.5 \% \mathrm{w} / \mathrm{w}$ (Iyengar et al., 1976) but symptoms in citrus occurred 3 to 15 weeks after application when biuret levels in urea exceeded as little as $0.35 \% \mathrm{w} / \mathrm{w}$ (Oberbacher, 1954). Chlorotic symptoms caused by biuret toxicity first appear at the leaf tip and margin, and spread to more of the leaf area as the biuret content increases. The amount of visible chlorosis symptoms was directly proportional to the amount of biuret content in the urea (Iyengar et al., 1976; Oberbacher, 1954). In later studies, biuret toxicity symptoms in citrus leaves usually did not appear earlier than 30 to $45 \mathrm{~d}$ after spray application (Albrigo, 2002), but included leaf

Received for publication 8 Dec. 2004. Accepted for publication 3 Apr. 2005. This research was supported by the Florida Agricultural Experiment Station and approved for publication as Journal Series No. R-09828. 'EM Laboratory Manager.

${ }^{2}$ Professor. Corresponding author: phone: 863/956-1151; fax: 863/956-4631; e-mail: albrigo@lal.ufl.edu deformation when rates of biuret were near $2 \% \mathrm{w} / \mathrm{w}$ of urea and sprayed on developing foliage. Once biuret-induced chlorosis occurred in citrus, the affected area of the leaf did not recover a green color (Albrigo, 2002; Oberbacher, 1954).

Albrigo (2002), Jones (1954), and Robinson (1978) did not find any serious yield effects from one or two sprays using urea with up to $1.0 \%$ or $0.8 \%$ biuret, respectively. Most of these studies did not use similar rates per leaf area, so direct comparisons between crop species are not possible. In common, however, is the unusual permanent nature of the chlorosis. A similar phenomenon has been observed in many plants in response to some herbicides (Anderson and Thomson, 1973). Chlorosis is generally recognized as a loss of the quantity and quality of chloroplasts (Gepstein, 1988). Many foliar diseases, nutritional deficiencies and senescence also lead to chlorosis of parts or whole leaves (Butler and Simon, 1971; Klotz, 1978; Smith, 1966; Thomson and Platt-Aloia, 1976; Wallace, 1978). However, nutritional chlorosis is considered to be temporary up to a certain point (Hecht-Bucholz and Ortmann, 1986; Stoddart and Thomas 1982), since the leaf is able to re-green in time when the missing nutrient is added. This is particularly noted for $\mathrm{Zn}, \mathrm{Mn}$, and some other minor element deficiencies (Plucknett and Sprague, 1989; Smith, 1966).

Leaf yellowing is different from senescence in most plants. Once a leaf reaches a certain point in the chlorophyll degradation process, it apparently no longer can re-green and the leaf dies (Freeman et al., 1978). Most plants have a natural mechanism for degradation of chloroplasts and re-absorption of their breakdown compounds into twigs as leaves senesce (Woolhouse, 1987). Ultrastructural and lipid changes in chloroplasts as they revert to chromoplasts have been reported in citrus (Freeman et al., 1978). Similar to the process of re-greening in other crops after special treatment (Greening et al., 1982; Sveshvikova et al., 1966), orange 
fruit flavedo cell chloroplasts can convert to chromoplasts and then revert back to chloroplasts naturally (Thomson et al., 1967). Thomson et al. (1967) state that during re-greening, membrane vesicles form from the inner portion of the plastid membrane. Some vesicles are found in the stroma and others are associated with developing grana, following the same developmental pattern as the conversion of proplastids to chloroplastids. There is also a gradual reduction in the size and number of large plastoglobuli located in the chromoplasts, indicating that these globules may be the substrate for the lipids in the formation of the internal membrane system.

The purpose of this study was to evaluate ultrastructural changes of citrus leaves after exposure to biuret/urea and compare these changes to those taking place in citrus leaves experiencing zinc deficiency or age-related senescence. The question to be answered was: Is there a similarity of ultrastructure in biuretaffected chloroplasts to the ultrastructure of chloroplasts that are capable of re-greening as in nutritional deficiency or to the ultrastructure associated with the permanently chlorotic plastids, gerontoplasts (Matile, 1992), in citrus and other plant species? Ultimately, what are the ultrastructural characteristics responsible for the permanency of biuret-induced chlorosis?

\section{Materials and Methods}

Small limbs (1 to $2 \mathrm{~cm}$ diameter) of trees of 'Ruby Red' grapefruit and 'Hamlin' orange were sprayed with a solution of $1.05 \%$ biuret/urea (w/w) at a rate of $16.8 \mathrm{~kg} \mathrm{~N}$ in $1169 \mathrm{~L}$ water per hectare to thoroughly wet the leaves. The treated leaves were the fully expanded nonhardened spring leaves. Forty-five days later, samples from unsprayed tree limbs of fully expanded and time hardened sun leaves showing no visible symptoms and leaf samples from sprayed tree limbs showing slight or severe chlorosis (hereafter referred to as treatments) were prepared for transmission electron microscopy (TEM). All samples were taken between 1000 and 1200 HR. The samples were fixed in 3\% glutaraldehyde in $0.1 \mathrm{M}$ potassium phosphate buffer $\mathrm{pH} 7.2$ for $4 \mathrm{~h}$ at room temperature, then washed in buffer and post fixed in $2 \%$ osmium tetroxide solution made with the same buffer for $4 \mathrm{~h}$. After dehydration in an acetone series, the samples were embedded in Spurr's resin (Spurr, 1969). Sample blocks were sectioned and stained with uranyl acetate (Stempak and Ward, 1964) and lead citrate (Reynolds, 1963). Thin sections were observed on a Philips 201 TEM (FEI Co., Hillsboro, Ore.).

Samples of 2-year-old age-related senescent leaves, showing chlorosis from both leaf surfaces and chlorosis of the adaxial surface while greenish on the abaxial surface, were sampled from nearby trees that were not sprayed with urea and prepared for TEM using the above method. Orange and grapefruit fully expanded, hardened, summer leaves having visible zinc deficiency (Smith, 1966) were also prepared in the same manner for comparison. Typical interveinal chlorotic bands were selected for preparation. All samples were taken between 1000 and 1200 HR. Similar chlorotic and non-chlorotic leaf tissues from orange and grapefruit trees were air dried and sent to a plant tissue analytical laboratory to verify $\mathrm{Zn}$ status.

Cross sections of biuret-sprayed leaf samples showing slight chlorosis, advanced chlorosis and controls of orange and grapefruit were examined with the TEM. A total of 20 micrographs from five different blocks per treatment were acquired. From these micrographs, length and width measurements were made of the cells and vacuoles of 50 cells to determine the approximate percentage of area occupied by the vacuoles. Measurements were made of cells that appeared to be sectioned through their longitudinal center. This was determined subjectively by looking for cells exhibiting the maximum amount of vacuolar space with chloroplasts only around the periphery and sharply defined walls compared to cells with chloroplasts nearer the center of the cell section, indicating a more tangential section. Approximate cross-sectional areas of the cells and vacuoles were determined using the formula for the area of an ellipse. The area of the vacuole was then calculated as a percentage of the area occupied within the cell walls of 50 cells per treatment. One-way analysis of variance was performed and, when appropriate, significant differences were determined using Duncan's multiple range test (SAS version 8; SAS Institute, Cary, N.C.). To confirm the above measurements 50 cells per treatment were measured using Image-Pro Plus Version 4.1image analysis system (Media Cybernetics, Silver Springs, Md.). The areas of the vacuoles and whole cells were measured and divided to determine percent vacuolar area. Average percentages and standard deviations were calculated per treatment. One-way analysis of variance and significant differences were determined using Duncan's multiple range test.

Chloroplasts in the same micrographs as described above were examined to quantify the number of chloroplasts per cell in 50 different cells per treatments. To quantify the change in the size of the chloroplasts, length and width measurements were made of 50 chloroplasts per treatment. Chloroplasts with clearly defined outer membranes, indicating that the chloroplasts were cut near the middle rather than the edges where membranes would be oblique, were selected for measurement. Approximate size of the chloroplasts was determined using the formula for the area of an ellipse. Average numbers of chloroplasts per cell and area per chloroplasts were determined. One-way analysis of variance was performed and significant differences were determined using Duncan's multiple range test.

\section{Results}

Sections of the nonchlorotic grapefruit control leaves (Fig. 1 A and B) revealed palisade cells full of large chloroplasts filled with starch and a few plastoglobuli. Nuclei were prominent and the central vacuole occupied, on average, only about $36 \%$ of the cell area in longitudinal sections (Table 1). In the leaves showing slight biuret-induced chlorosis (Fig. $1 \mathrm{C}$ and D), there were fewer, smaller chloroplasts. The central vacuole occupied $\approx 50 \%$ of the cell area due to the smaller volume of cytoplasm (Table 1). The chloroplasts still retained some starch and the plastoglobuli had increased in number and size. In the severely chlorotic samples (Fig. $1 \mathrm{E}$ and F), there were very few chloroplasts and their average size was about one-fifth of that in the control leaf cells (Table 1). The amount of cytoplasm was reduced even more, with the central vacuole filling $60 \%$ of the viewed surface area of the palisade cells (Table 1). The plastids looked more like chromoplasts with no grana or other internal membranes and large numbers of plastoglobuli.

The cross sections of orange leaves from controls (Fig. $2 \mathrm{~A}$ and B) were very similar in appearance to the grapefruit control leaves with the palisade cells containing large numbers of chloroplasts in the cytoplasm, which occupied one-half to two-thirds of the longitudinal area (Table 1). The nuclei were also prominent and the central vacuoles were broken into smaller compartments occupying about one-third of the cell's longitudinal area (Table 1). The chloroplasts were large, filled with starch and several small 




Fig. 1. (A and $\mathbf{B})$ control grapefruit leaf palisade cells and chloroplasts; ( $\mathbf{C}$ and D) from grapefruit leaves expressing slight chlorosis from biuret treatment. Note the increased vacuolar volume and reduced size of starch grains compared to the control cells. ( $\mathbf{E}$ and $\mathbf{F}$ ) from grapefruit leaves expressing severe chlorosis from biuret treatment. Note the further increased vacuolar volume, reduction in size and number of plastids, total lack of starch and the increased number of plastoglobuli ( $\mathrm{s}=$ starch, $\mathrm{g}=$ granal stacks, $\mathrm{p}=$ plastoglobuli).

plastoglobuli. As with grapefruit, the slightly chlorotic samples from biuret sprays (Fig. $2 \mathrm{C}$ and D) had fewer chloroplasts, which were smaller in size than in the controls (Table 1). The amount of cytoplasm was reduced and the central vacuole filled about one-half of the cell's longitudinal area (Table 1). The chloroplasts still had a few starch grains, large plastoglobuli and evidence of a few granal stacks. The cells in severely chlorotic samples (Fig. 2 $\mathrm{E}$ and F) had very little cytoplasm and the individual chloroplasts

Table 1. Percent vacuolar content per total cell volume, average numbers of chloroplasts per cell, and average area per chloroplast over three levels of chlorosis related to biuret toxicity in orange and grapefruit leaves.

\begin{tabular}{|c|c|c|c|c|}
\hline \multirow[t]{2}{*}{ Treatment } & \multicolumn{2}{|c|}{$\begin{array}{l}\text { Vacuolar } \\
\text { content } \\
(\%)\end{array}$} & \multirow[t]{2}{*}{$\begin{array}{l}\text { Avg chloroplasts } \\
\text { per cell } \\
\text { (no.) }\end{array}$} & \multirow[t]{2}{*}{$\begin{array}{l}\text { Avg area per } \\
\text { chloroplast } \\
\left(\mu \mathrm{m}^{2}\right)\end{array}$} \\
\hline & $\mathrm{GFz}$ & IPy & & \\
\hline Orange - control & $\overline{39 c^{x}}$ & $\overline{45 \mathrm{c}}$ & $6.46 \mathrm{a}$ & $33.38 \mathrm{a}$ \\
\hline Orange - slight chlorosis & $53 \mathrm{~b}$ & $55 \mathrm{~b}$ & $5.02 \mathrm{~b}$ & $21.86 \mathrm{~b}$ \\
\hline Orange - severe chlorosis & $63 \mathrm{a}$ & $63 \mathrm{a}$ & $3.70 \mathrm{c}$ & $20.19 \mathrm{~b}$ \\
\hline Grapefruit - control & $36 \mathrm{c}$ & $42 \mathrm{c}$ & $5.52 \mathrm{a}$ & $45.71 \mathrm{a}$ \\
\hline Grapefruit - slight chlorosis & $48 \mathrm{~b}$ & $52 \mathrm{~b}$ & $4.51 \mathrm{~b}$ & $25.65 \mathrm{~b}$ \\
\hline Grapefruit - severe chlorosis & $63 \mathrm{a}$ & $69 \mathrm{a}$ & $2.62 \mathrm{c}$ & $7.86 \mathrm{c}$ \\
\hline
\end{tabular}

${ }^{2}$ Geometric formula.

yImage Pro.

×Duncan's multiple range test significant differences ( $5 \%$ level) are shown by different letters for each measurement or count for 50 cells or 50 chloroplasts. were about two-thirds the size of the control chloroplasts (Table $1)$. The central vacuoles of the severely chlorotic leaf cells occupied about $60 \%$ of the cell's longitudinal area (Table 1) and were broken into small compartments, as in the control. As in grapefruit, the plastids were more like chromoplasts containing many plastoglobuli, and there was little evidence of internal membranes.

To quantify the differences in chloroplast numbers and sizes, counts and measurements were made of the different treatments and controls. Table 1 shows that the numbers of chloroplasts per chlorotic cell were significantly reduced from the control cells in both grapefruit and orange across all levels of chlorosis. The sizes of the chloroplasts were significantly different in the grapefruit across all three conditions also. However, the average chloroplast sizes at the two chlorotic levels in orange were similar and only significantly different from the control.

Careful observation was made of the chloroplasts to assess the degradation mechanism in order to determine what might prevent them from regenerating if the effects of the biuret wore off. As noted above, there were fewer plastids in the chlorotic leaves compared to the control. There was also evidence that the plastoglobuli were moving from the chromoplasts to the cytoplasm or central vacuole. The plastoglobuli were expelled into the vacuoles in association with membrane bound vesicles (Fig. $3 \mathrm{~A}$ and B), or penetrated the outer membranes directly (Fig. $3 \mathrm{C}$ and D). The severely chlorotic samples possessed many plastoglobuli in the cytoplasm, free or membrane bound, and in the vacuole. The outer membranes of the chromoplasts in the severely chlorotic samples were not observed to degrade which would have allowed liberation of the entire contents.

Senescing leaves of citrus also were compared to the high biuret urea treated leaves to determine if there was a difference between irreversible senescence chlorosis and the chlorosis brought on by biuret application. The reduced number of chromoplasts in the senescent leaf cells of grapefruit and orange was similar to that observed in samples from severely chlorotic biuret treated leaves (Fig. $4 \mathrm{~A}$ and B, respectively). The presence of plastoglobuli and, in the case of grapefruit, vesicles within the chromoplasts are shown in Fig. $4 \mathrm{C}$ and D. The internal membrane system in the chromoplasts was nonexistent in orange. The liberation of the plastoglobuli through the outer membrane system of the chromoplasts in association with vesicles in grapefruit and directly in orange is shown in Fig. $4 \mathrm{E}$ and F, respectively. The association of membranes with the movement of lipids appeared to be an early stage of senescence, since at advanced chlorosis chloroplasts had little lipid content remaining, as shown here in the orange leaves and was also observed in grapefruit samples (not shown). The dissolution of the outer membrane systems of the plastids was never observed in senescent citrus leaves.

To compare biuret-induced and senescence chlorosis to chlorosis where re-greening is possible, representative mineral deficiency samples were taken from the same or adjacent trees. Classical zinc deficient areas in affected leaves were used (Plucknett and Sprague, 1989; Smith, 1966). Chlorotic zones in orange leaves had 16 to $19 \mu \mathrm{g} \cdot \mathrm{mL}^{-1} \mathrm{Zn}(\mathrm{DW})$ and nonchlorotic zones had 22 to $28 \mu \mathrm{g} \cdot \mathrm{mL}^{-1} \mathrm{Zn}$, while nonchlorotic leaves had 22 to $29 \mu \mathrm{g} \cdot \mathrm{mL}^{-1}$ $\mathrm{Zn}$. In grapefruit, chlorotic zones had 13 to 




Fig. 2. (A and $\mathbf{B}$ ) control orange leaf palisade cell layer and chloroplasts; ( $\mathbf{C}$ and D) from orange leaves expressing slight chlorosis from biuret treatment; (E and $\mathbf{F}$ ) from orange leaves expressing severe chlorosis from biuret treatment. Note the increased vacuolar volume, reduced number of plastids, lack of starch and increased number of plastoglobuli ( $\mathrm{s}=$ starch, $\mathrm{g}=$ granal stacks, $\mathrm{p}$ $=$ plastoglobuli).

$15 \mu \mathrm{g} \cdot \mathrm{mL}^{-1}$ while nonchlorotic zones were 14 to $16 \mu \mathrm{g} \cdot \mathrm{mL}^{-1}$ and green leaves were 16 to $51 \mu \mathrm{g} \cdot \mathrm{mL}^{-1}$. Zinc deficient cells in orange had fewer chloroplasts, less cytoplasm and larger vacuoles (Fig. 5B) compared with the cells in the healthy control orange leaves (Fig. 5A). The controls had prominent starch grains, but there was almost no starch in $\mathrm{Zn}$ deficient cells and plastoglobuli or lipid bodies accumulated in the plastids (Fig. 5C). There were still remnants of internal membranes in the chromoplasts in both orange and grapefruit leaf cells (arrows 5C, 5D, respectively).

In $\mathrm{Zn}$ deficient orange leaves a different form of plastoglobular movement was observed. Plastoglobuli or lipid bodies were observed expelled through the chloroplast membrane (Fig. 6A, arrows) and into the endoplasmic reticulum. Lipid bodies were also observed within the double layers of the nuclear membrane (Fig. 6 B and C arrows) and then in the interior of the nucleus (Fig. $6 \mathrm{D}$ arrows). This was observed many times and is not considered to be an artifact of fixation.

\section{Discussion}

Thomson (1966) has reported that the chloroplast-chromoplast transition in 'Valencia' oranges is accompanied by the formation of small plastoglobuli also found in the chloroplasts of senescing leaves (Butler and Simon, 1971). He also suggested that these globules may contribute to the formation of the large globules in the mature chromoplast. Mature oranges have the ability to re-green under natural conditions, regulated by sugar, nitrogen,



Fig. 3. (A) dissolution of chromoplast in grapefruit leaf expressing severe chlorosis from biuret treatment (arrow $=$ plastoglobulus in vacuole, $\mathrm{v}=$ plastoglobuli in vesicle in cytoplasm). (B) dissolution of chromoplast in orange leaf expressing severe chlorosis (arrow $=$ plastoglobuli in vesicles in vacuole $).(\mathbf{C}$ and $\mathbf{D})$ arrows point to expulsion of plastoglobulus in orange leaf expressing severe chlorosis. In all micrographs note that the outer membrane stays intact and the lipids are expelled through the outer membrane.

and phytohormone availability (Huff, 1983, 1984; Iglesias et al., 2001), as do leaves of tobacco (Nicotiana tabacum L.) when treated with kinetin (Sveshnikova et al., 1966). In this process, the chromoplasts revert back to chloroplasts, the globules disappearing as the thylakoids reform (Thomson et al. (1967), Biswal and Biswal (1988), Greening et al. (1982), Kessler et al. (1999), and Matile (1992) proposed that the lipids from the plastoglobuli are used during membrane formation.

The observation in this study that the plastoglobuli in the chromoplasts of biuret-affected and senescing cells were passed through the membrane and deposited in the cytoplasm or in the vacuole may preclude the use of these globules in the reformation of membranes. This may be why the chromoplasts in the biuret-affected leaves cannot revert back to chloroplasts after the biuret's influence has dissipated. The observation of the membrane remnants left in the plastids of the mineral deficient samples suggest that in order to re-green, there must be the presence of at least remnants of the internal membrane system. Grob and Rufner (1969) observed this in Spirodella oligorrhiza Hegelm. chloroplasts and suggested that only the presence of a rudimentary lamellar system was necessary for re-greening. Others (Gepstein, 1988; Thomson et al., 1967) suggested that new thylakoids develop from the inner membrane of the plastid's outer envelope. Since the envelope stayed intact in chromoplasts of biuret-affected and age-related senescent leaf cells, these plastids 


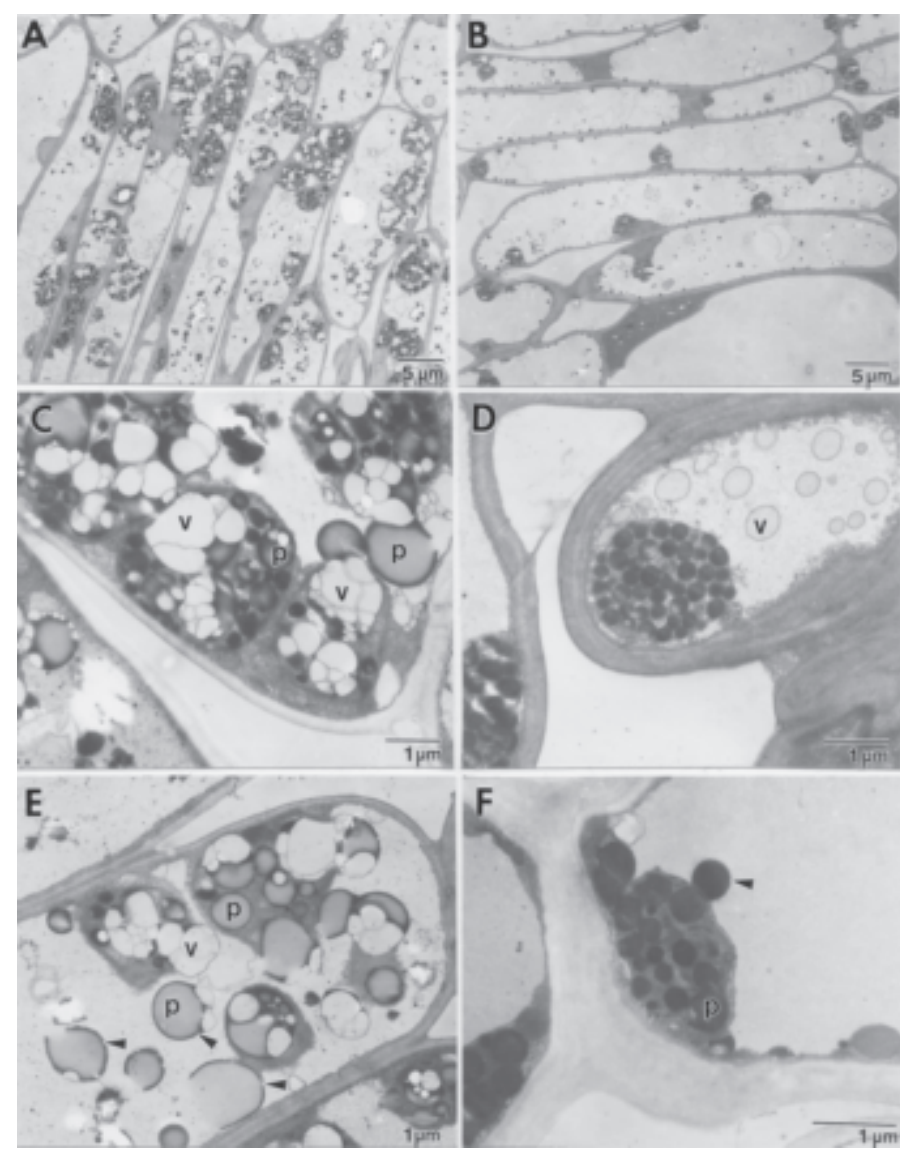

Fig. 4. (A, C, and $\mathbf{E}$ ) early stage of age-related senescence in grapefruit leaf. Note the apparent liberation of plastoglobuli (p) to the cytoplasm and vacuole in association with vesicles (v) presumably derived from the thylakoids. E: arrows $=$ plastoglobuli in vacuole. $(\mathbf{B}, \mathbf{D}$, and $\mathbf{F})$ late stage of age-related senescence in orange leaf showing the diminished number of gerontoplasts compared to the controls shown previously. F: arrow = plastoglobulus extruding through outer membrane.

should be able to regenerate into chloroplasts. The indication that chloroplast regeneration does not occur supports the concept of Greening et al. (1982), that re-greening is not possible without some internal lipid store.

There are two proposals regarding the loss of photosynthetic activity during senescence (Gepstein, 1988). One is that the total number of chloroplasts in the mesophyll declines. The other proposal is that the autonomous and sequential degradation of the individual chloroplast constituents leads to a decline in photosynthetic activity. In this study, both situations were observed in the senescent and biuret-treated samples. Particularly in biuretaffected samples, there appeared to be fewer and smaller chloroplasts in the mesophyll cells in the severely chlorotic tissue, and we observed the gradual breakdown and release into the vacuole or cytoplasm of the internal constituents of the chloroplasts.

The sequential steps to plastid breakdown during senescence determined from many studies (Freeman et al., 1978; Gepstein, 1988; Thomas, 1977; Thomas and Stoddart, 1980; Woolhouse, 1987) are as follows: Initially, stroma thylakoids vesiculate and lose their integrity. There is a gradual increase in the volume and number of plastoglobuli. The grana thylakoids swell and then undergo gradual disintegration. There is a marked decrease in the size of the plastids (Barton, 1966) and a reduction in electron density, buoyant density, a loss of ribosomes and DNA contents. It


Fig. 5. (A) orange control leaf. s - starch. (B and $\mathbf{C}$ ) orange leaf with zinc deficiency. Note the number of chromoplasts is less than that of controls. Also there is less starch and an increase in number of plastoglobuli. C: note the persistence of granal stacks (arrow). D: chromoplast from grapefruit leaf with zinc deficiency. Note the large numbers of plastoglobuli (p) and persistence of internal membranes (arrows).

is also suggested that there is a loss of the capacity of division and biosynthesis (Biswal and Biswal, 1988; Matile, 1992). Generally, the chloroplast envelope retains its integrity until after the internal membranes are completely dissipated. It is this outer envelope that is believed to control the process of export of materials during leaf senescence (Sexton and Woolhouse, 1984).

The sequence of senescence observed in citrus was slightly different. Instead of the build-up and loss of plastoglobuli at the final step when the membrane dissipates, in citrus senescence there is loss of plastoglobuli by their liberation in association with membrane vesicles or directly through the double membrane envelope. Contrary to the report by Matile (1992) that the plastoglobuli are the final depository of thylakoidal lipids, this study, as well as that of Wittenback et al. (1982), suggests that the vacuole and cytoplasm may be the final depository within the cell. These bodies were observed in both the cytoplasm, associated with membranes, and in the vacuoles. Guiamét et al. (1999) described this type of secretion of lipids, pigments, and proteins from senescing chloroplasts in soybean and related this secretion to the breakdown of photosynthetic membranes.

Another possible means of dissipation of lipids from chloroplasts was observed in the Zn deficient leaves in this study. Lipids were observed as plastoglobuli in the plastids and as inclusions between the double outer membranes of the plastids. They were also observed between membranes of the endoplasmic reticulum. In other cells in the same sections the lipids were found between the double membranes of the nucleus and in the interior of the nucleus. This suggests a process whereby the lipids from the chloroplasts relocate in the nucleus by way of the endoplasmic reticulum. These observations have not been previously reported. The leaf tissue $\mathrm{Zn}$ levels in all of the samples were moderately low to deficient, but the low levels in the chlorotic leaf bands was clearly deficient and appropriate for these comparisons. Severe $\mathrm{Zn}$ deficiency in citrus is considered to occur when leaf levels are below $18 \mu \mathrm{g} \cdot \mathrm{mL}^{-1} \mathrm{Zn}$ (Smith, 1966), and the chlorotic bands contained $<16 \mu \mathrm{g} \cdot \mathrm{mL}^{-1}$. 




Fig. 6. Unusual dispersal of lipid in orange leaves showing zinc deficiency. (A) lipid is shown in the interior of the plastid (pl), between the plastid's double membranes (arrows), and in the endoplasmic reticulum (er). (B) lipid in the double nuclear membrane (arrows); $\mathrm{n}=$ nucleus. (C) higher magnification of B showing the presence of lipid in the endoplasmic reticulum (er) and also in the nuclear membrane (arrows). (D) lipids present (arrows) in the interior of the nucleus $(\mathrm{n})$

Another observation made in this study was that the crosssectional area of chloroplasts differed within the chlorotic states of orange and grapefruit. Table 1 shows that the sizes of the chloroplasts demonstrating mild and severe chlorosis in orange were not significantly different whereas in grapefruit, the sizes of the chloroplasts in these two states were significantly different. We have not tested a possible greater sensitivity to biuret in grapefruit, but the observations suggest that biuret could have a more pronounced effect on grapefruit productivity compared to orange. Little or no reduction in orange yields was found from two urea sprays containing $0.8 \%$ biuret (Albrigo, 2002), but similar tests were not reported for grapefruit. While severe biuret toxicity reduced chloroplast size significantly only in grapefruit, numbers of chloroplasts were significantly reduced in both oranges and grapefruit with biuret severity (Table 1). This would explain the visual similarity in appearance of the chlorotic states between the two species.

As noted in Methods, two means of determining vacuolar area was used in this study. The results indicated that the means determined by geometric formula fell within the standard deviation of results determined by Image-Pro image analysis system. The significance of this is that where a software analysis system is not available, simple length/width measurements and a geometric formula can reliably be used.

In conclusion, it was found that, after biuret treatment of leaves, chloroplasts lost their store of plastoglobuli (lipid bodies) and all evidence of internal membranes whereas chloroplasts from leaves with $\mathrm{Zn}$ deficiency retained both. Chloroplasts from agerelated senescent citrus leaves also lost both the plastoglobuli and internal membrane systems. Thus we propose that chlorosis from biuret toxicity is more similar to senescence than mineral deficiency chlorosis in citrus. Further, loss of both lipid stores and internal membranes appears to relate to inability of plastids to recover from chlorosis in citrus.

\section{Literature Cited}

Albrigo, L.G. and J.W. Grosser. 1996. Methods for evaluation of spray chemical phytotoxicity to citrus. Proc. Fla. State Hort. Soc. 109:52-57.

Albrigo, L.G. 1999. Effects of foliar applications of urea or Nutriphite on flowering and yields of Valencia orange trees. Proc. Fla. State Hort. Soc. 112:1-4.

Albrigo, L.G. 2002. Foliar uptake of N-P-K sources and urea biuret tolerance in citrus. In: M. Tagliavini, M. Toselli, L. Bertschinger, P. Brown, D. Neilsen, and M. Thalheimer (eds.). Proc. Intl. Symp. Foliar Nutrition of Perennial Fruit Plants. Acta Hort. 594:627-633.

Anderson, J.L. and W.W. Thomson. 1973. The effects of herbicides on the ultrastructure of plant cells. Residue Rev. 47:167-189.

Barton, R. 1966. Fine structure of mesophyll cells in senescing leaves of Phaseolus. Planta 71:314-325.

Biswal, U.C. and B. Biswal. 1988. Ultrastructural modifications and biochemical changes during senescence of chloroplasts. Intl. Rev. Cytol. 113:271-321.

Butler, R. and E. Simon. 1971. Ultrastructural aspects of senescence in plants. Adv. Gerontology Res. 3:73-129.

Freeman, B.A., K. Platt-Aloia, J.B. Mudd, and W.W. Thomson. 1978. Ultrastructural and lipid changes associated with the aging of citrus leaves. Protoplasma 94:221-233.

Gepstein, S. 1988. Photosynthesis, p. 85-109. In: L.D. Nooden and A.C. Lepold (eds.). Senescence and aging in plants. Academic, San Diego.

Gooding, M.J. and W.P. Davies. 1992. Foliar urea fertilization of cereals: A review. Fert. Res. 32:209-222.

Greening, M.T., F.J. Butterfield, and N. Harris. 1982. Chloroplast ultrastructure during senescence and regreening of flax cotyledons. New Phytol. 92:279-285.

Grob, E.C. and J. Rufner. 1969. Influence of sugar containing nutrients on ultrastructure and photosynthetic activity of Spirodella oligorrhiza chloroplasts, p. 56-62. In: H. Metzner (ed.). Progress in photosynthesis research. vol. 1. Institut fur Chemische Pflanzenphysiologie, Tubingen, Germany.

Guiamét, J.J., E. Pichersky, and L.D. Noodén. 1999. Mass exodus from senescing soybean chloroplasts. Plant Cell Physiol. 40:986-992.

Hecht-Buchholz, C.H. and U. Ortmann. 1986. Effect of foliar iron application on regreening and chloroplast development in iron-chlorotic soybean. J. Plant Nutr. 9:647-659.

Huff, A. 1983. Nutritional control of regreening and degreening in citrus peel segments. Plant Physiol. 73:243-249.

Huff, A. 1984. Sugar regulation of plastid interconversions in epicarp of citrus fruit. Plant Physiol. 76:307-312.

Iglesias, D.J., F.R. Tadeo, F. Legaz, E. Primo-Millo, and M. Talon. 2001. In vivo sucrose stimulation of colour changes in citrus fruit epicarps: Interactions between nutritional and hormonal signals. Physiologia Plantarum 112:244-250.

Iyengar, B.R.V., C.S. Krishnappa Naik, and S.G. Bakre. 1976. Biuret toxicity in Arabica coffee. J. Coffee Res. 6:26-28.

Jones, W.W. 1954. Biuret toxicity of urea foliage sprays on citrus. Science 120:499-500.

Kessler, F., D. Schnell, and G. Blobel. 1999. Identification of proteins associated with plastoglobules isolated from pea (Pisum sativum L.) chloroplasts. Planta 208:107-113.

Khemira, H., E. Sanchez, T.L. Righetti, and A.N. Azarenko. 2000. Phytotoxicity of urea and biuret sprays to apple foliage. J. Plant Nutr. 23:35-40.

Klotz, L.J. 1978. Fungal, bacterial, and nonparasitic diseases and injuries originating in the seedbed, nursery, and orchard, p. 2-62. In: W. Reuther, E.C. Calavan, and G.E. Carnan (eds.). The citrus industry. vol. IV. Univ. of California, Div. Agr. Sci., Berkeley.

Matile, P. 1992. Chloroplast senescence, p. 413-440. In: B.R Baker and H. Thomas (eds.). Crop photosynthesis: Spatial and temporal determinants. Elsevier, Amsterdam, The Netherlands.

Oberbacher, M.F. 1954. A chlorosis of citrus produced by biuret as an 
impurity in urea. Proc. Fla. State Hort. Soc. 67:67-69.

Plucknett, D.L. and H.B. Sprague (eds.). 1989. Detecting mineral nutrient deficiencies in tropical and temperate crops. Westview Press, Boulder, Colo.

Reynolds, E.S. 1963. The use of lead citrate at high $\mathrm{pH}$ as an electronopaque stain for electron microscopy. J. Cell Biol. 17:208-212.

Robinson, J.B. 1978. The biuret content of urea for foliar application to citrus. Intl. Soc. Citricult. Univ. of Sydney, Sydney, Australia.

Sanford, W.G., D.P. Gowing, H.Y. Young, and R.W. Leeper. 1954. Toxicity to pineapple plants of biuret found in urea fertilizers from different sources. Science 120:349-350.

Sexton, R. and H.W. Woolhouse. 1984. Senescence and abscission, p. 467-497. In: M.B. Wilkins (ed.). Advanced plant physiology. Pitman Press, London.

Smith, P. 1966. Citrus nutrition, p. 174-207. In: N.F. Childers (ed.). Nutrition of fruit crops: Tropical, sub-tropical and temperate tree and small fruits. Somerset Press, Somerville, N.J.

Spurr, A.R. 1969. A low viscosity resin embedding medium for electron microscopy. J. Ultrastructural Res. 26:697-701.

Stempack, J.C. and R.T. Ward. 1964. An improved staining method for electron microscopy. J. Cell Biol. 22:697-701.

Stoddart, L. and H. Thomas. 1982. Leaf senescence, p. 592-636. In: Encyclopedia of plant physiology. New series. vol. 14A. SpringerVerlag, Berlin, N.Y.

Sveshnikova, I.N., O.N. Kulaeva, and Y.P. Bolyakina. 1966. Formation of lamellae and granae in the chloroplasts of yellow leaves induced by 6-benzylaminopurine. Soviet Plant Physiol. 13:133-9.

Thomas, H. 1977. Ultrastructure, polypeptide composition and photochemical activity of chloroplasts during foliar senescence of a non-yellowing mutant genotype of Festuca pratensis Huds. Planta 137:53-60.

Thomas, H. and J.L. Stoddart. 1980. Leaf senescence. Ann. Rev. Plant Physiol. 31:83-111.

Thomson, W.W. 1966. Ultrastructural development of chromoplasts in Valencia oranges. Bot. Gaz. 127(2-3):133-139.

Thomson, W.W., L.N. Lewis, and C.W. Coggins. 1967. The reverson of chromoplasts to chloroplasts in Valencia oranges. Cytologia 32:117-124

Thomson, W.W. and K. Platt-Aloia. 1976. Ultrastructure of the epidermis of developing, ripening, and senescing navel oranges. Hilgardia 44:61-82.

Wallace, J.M. 1978. Virus and virus-like diseases, p. 69-173. In: W. Reuther, E.E. Calavan, and G.E. Carnan (eds.). The citrus industry. vol. IV. Univ. of California, Div. Agr. Sci., Berkeley.

Wittenbach, V.A., W. Lin, and R.R. Hebert. 1982. Vacuolar localization of proteases and degradation of chloroplasts in mesophyll protoplasts from senescing primary wheat leaves. Plant Physiol. 69:98-102.

Woolhouse, H.W. 1987. Regulation of senescence in the chloroplast, p. 132-145. In: W.W. Thomson, E.A. Nothnagel, and R.C. Huffaker (eds.). Plant senescence: Its biochemistry and physiology. Amer. Soc. Plant Physiol., Rockville, Md. 